\title{
(In)acessibilidade digital
}

\author{
Digital (in)accessibility
}

\author{
Laís C. Licheski, Luciane Maria Fadel
}

acessibilidade, internet, w3c

accessibility, internet, w3c

\begin{abstract}
Este artigo verifica a acessibilidade digital no Portal Brasil. Para tanto, revê brevemente as normativas sobre acessibilidade digital em nível nacional e internacional e aplica o checklist sugerido pelo e-MAG no Portal, além das recomendações do WCAG 2.o. Os resultados apontam que, embora este checklist indique apenas quatro itens para verificação da acessibilidade, nenhum destes itens pode ser encontrado plenamente aplicado no Portal. Tampouco foram verificadas todas as recomendações listadas no documento no WCAG 2.0, sendo que a opção de mídias alternativas e controle das funcionalidades da interface pelo teclado são as que merecem mais atenção. Assim, este artigo alerta para a necessidade de projetos de interfaces baseados em consultas e envolvimento direto com potenciais usuários para minimizar os erros ao aplicar as recomendações do documento WCAG 2.o.
\end{abstract}

This paper verifies the digital accessibility in the Portal Brazil. Therefore, it starts with a brief review on the normative for digital accessibility at national and international levels and uses a checklist suggested by e-MAG in order to verify the accessibility of the Portal. In addition, the WCAG 2.0 recommendations on the Portal are verified. The results indicate that none of the four items discriminated at the checklist could be totally verified. Neither was the recommendations listed in the WCAG 2.0 document where the guidelines time based media, adaptable and keyboard access need more attention. Therefore, this paper alerts for the urge of interface projects based on the direct participation of the potential users to minimize errors applying the Web Content Accessibility Guidelines WCAG 2.0.

\section{Introdução}

Compreende-se acessibilidade digital como a viabilização do acesso à tecnologia da informação pelo maior número de pessoas possível, até mesmo por indivíduos com alguma deficiência e que necessitem de uma interface especial (FERREIRA, 2007). Assim, um projeto que se preocupa com acessibilidade vai além de uma boa interface e de uma navegação intuitiva, mas procura prover os meios para que indivíduos portadores de algum tipo de necessidade especial possam também usufruir das informações da forma mais natural possível (FREITAS, 2002). Portanto, acessibilidade digital compreende o design inclusivo 
e a oferta de produtos e serviços que cubram as necessidades de diferentes populações.

A acessibilidade pode ser obtida com o uso de um sistema automático de transcrição de mídias ou de sistemas que maximizam as habilidades dos usuários (ajuda técnica), como sistemas de leitura de tela, sistemas de reconhecimento da fala, simuladores de teclado, etc. Para algumas pessoas, a ajuda técnica é necessária para a melhoria da forma como desempenham suas atividades; para outras, é imprescindível como forma de expressão. Portanto, a acessibilidade tem o papel de auxiliar no desenvolvimento de um mundo melhor e semelhante para todas as pessoas, ampliando a possibilidade de proporcionar uma experiência satisfatória na utilização de qualquer tipo de interface, incluindo páginas para a Web. Interfaces Web, quando idealizadas e desenvolvidas com vistas à acessibilidade, oferecem melhor utilização e interpretação pelo navegador que auxilia as tecnologias assistivas a adequar o conteúdo ao público Portador de Necessidades Especiais (PNE).

Este artigo sugere que a acessibilidade, seja de sistemas, informação e/ou conhecimentos, não deva ser pensada apenas no contexto de pessoas com deficiências, mas a partir da diversidade de usuários: design para todos para uma sociedade inclusiva (digital e social). O desenvolvimento de projetos de design acessível e inclusivo deve levar em conta adaptações específicas para cada contexto, ou seja, ser flexível para se adaptar a cada cenário e seus participantes. Dentro desta perspectiva, este artigo propõe-se a verificar como a acessibilidade digital tem sido tratada em sites do governo, uma vez que as informações ali contidas deveriam chegar a todos os cidadãos. Para tanto, é realizada com uma breve revisão da padronização da acessibilidade Web, especificamente as recomendações do World Wide Web Consortium (w3c) e pelo e-MAG e verifica-se como estas indicações estão sendo aplicadas no Portal Brasil (http://www.brasil. gov.br).

\section{Documentos de padronização}

As investigações sobre acessibilidade Web ainda são recentes, tornando necessários estudos para se desenvolverem critérios que sirvam como padrões. Para entender e aplicar esses critérios em interfaces Web, empresas internacionais começaram a incorporar conceitos de acessibilidade no desenvolvimento de seus produtos (Sistema operacional Windows 7, Sistema operacional Mac, iPhone, Android, BlackBerry). Além dessas empresas, grupos internacionais tais como World Wide Web Consortium (w3c) promovem pesquisas e melhorias no desenvolvimento de interfaces Web e criam documentos de padronização com o objetivo de satisfazer as necessidades de usuários com necessidades especiais que irão utilizar sistemas planejados para a rede mundial de computadores. 
As recomendações do w3C para a construção de páginas Web e outros documentos disponibilizados no espaço digital podem ser resumidas por esses princípios:

- Assegurar uma transformação harmoniosa da informação, apresentando-a de mais de uma forma, p.ex.: áudio com versão em texto.

- Fazer o conteúdo compreensível e navegável, evitando dificuldades em compreender a informação, seja devido ao idioma, seja devido ao contexto no qual ela é apresentada.

Além disso, o w3C criou um documento de recomendações intitulado Web Content Accessibility Guidelines (WCAG 2.0) e critérios de acessibilidade para servir de base para a aplicação nas páginas Web para Portadores de Necessidades Especiais (PNE). Os PNE englobam um amplo grupo de pessoas com deficiência, incluindo cegueira e baixa visão, surdez e baixa audição, dificuldades de aprendizagem, limitações cognitivas, limitações de movimentos, incapacidade de fala, fotossensibilidade e suas combinações (WCAG 2.0, 2012).

O documento do w3c é encontrado na língua inglesa, o que para desenvolvedores e designers que não dominam essa língua pode ser um problema, devido à complexidade no entendimento das regras. Já o documento de recomendações (WCAG 2.0) foi traduzido para o português em março de 2009 pelo Prof. Everaldo Bechara (w3C, 2013).

\subsection{WCAG 2.0}

Os critérios que são utilizados pelo WCAG 2.0 são apresentados como declarações testáveis que, segundo o documento, não são para uma tecnologia específica. Devido à complexidade de aplicação dos critérios, é possível que haja certa dificuldade em entender o funcionamento do documento. Isto porque o WCAG 2.0 apresenta vários níveis de abordagem, que incluem princípios, recomendações de caráter geral, critérios de sucesso testáveis, um grande conjunto de técnicas, além de mostrar falhas comuns documentadas com exemplos, links para recursos e código fonte (WCAG 2.0, 2012).

No topo dessa hierarquia estão quatro princípios que representam a base da acessibilidade Web: perceptível, operável, compreensível e robusto. Para cada um desses princípios são listadas recomendações que ao todo reúnem 12 objetivos básicos que os autores para Web devem atingir para tornar seu conteúdo acessível. Além disto, para cada recomendação existem critérios testáveis de sucesso, para quando há necessidade de testes de conformidade. O documento prevê três níveis de conformidade dependendo do grupo a ser atendido (A para o mais baixo, AA e AAA para o nível mais elevado).

Além das recomendações e critérios de sucesso previstos, o w3C documenta técnicas de caráter informativo em duas categorias: tipo 
suficiente e tipo aconselhada. As técnicas de tipo suficiente vão de encontro aos critérios de sucesso estabelecidos pelo WCAG 2.0; as de tipo aconselhada vão além do que é requerido em cada um dos critérios de sucesso e permite aos autores um melhor cumprimento das recomendações, aproximando-se das barreiras de acessibilidade ainda não abrangidas pelos critérios de sucesso testáveis (ver Figura 1).

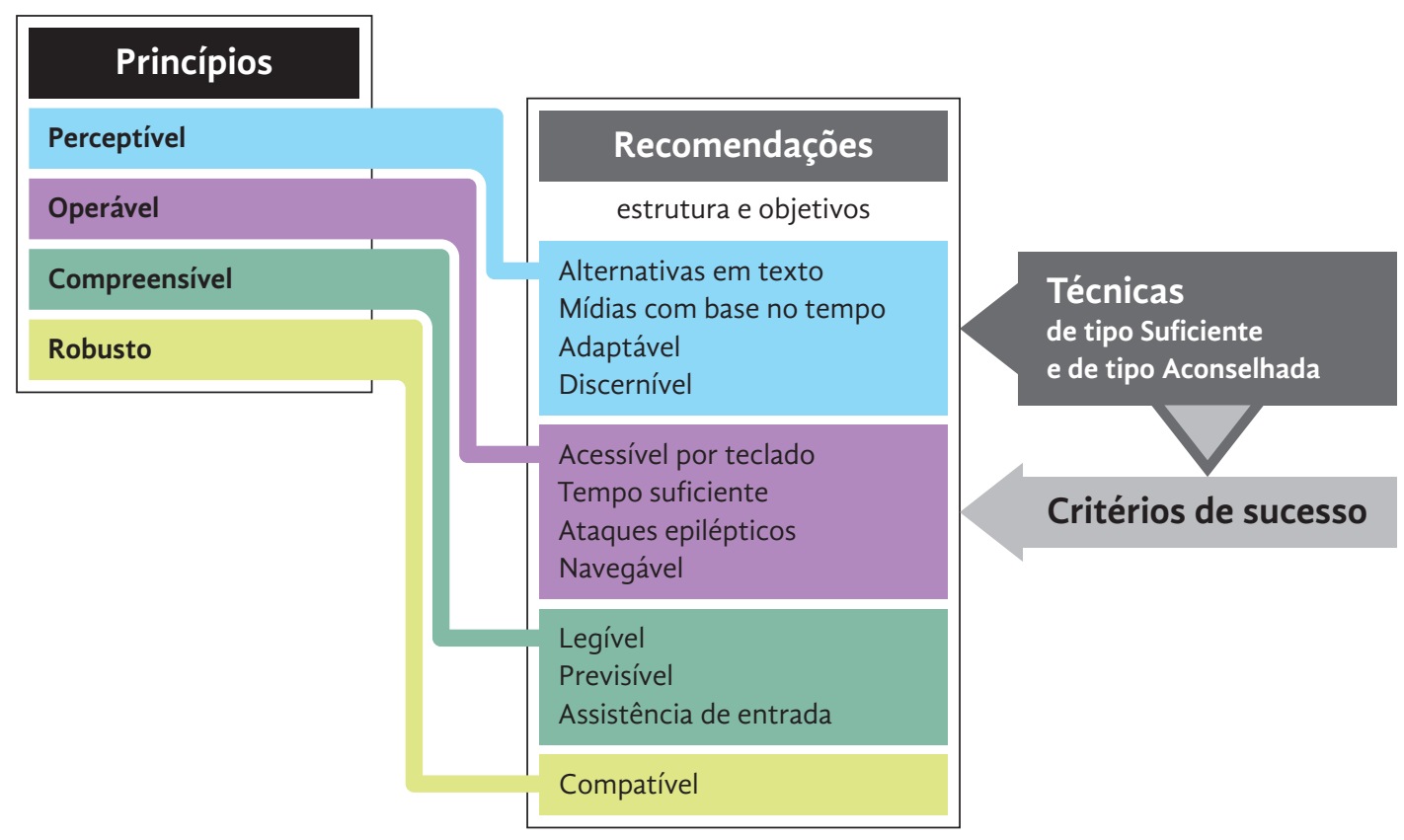

Figura 1 Níveis de abordagem das WCAG 2.0

Mesmo que a página Web esteja preparada para um tipo de PNE, ela pode não estar pronta para outros usuários de outros níveis de necessidades especiais. Assim, os autores de sistemas para Web são encorajados pelo $\mathrm{W} 3 \mathrm{C}$ a levar em consideração as técnicas atuais incluindo as de tipo aconselhada, sugerindo ainda "a procura por conselhos relevantes sobre as melhores práticas atuais, de forma a garantir que o conteúdo da Web seja acessível para a população PNE” (WCAG 2.0, 2012).

\section{2 e-MAG}

Com o objetivo de "facilitar o acesso para todas as pessoas às informações e serviços disponibilizados nos sítios e portais do governo", em 2005, o governo brasileiro lançou o Modelo de Acessibilidade de Governo Eletrônico - e-MAG (BRASIL, 2011). O e-MAG define os padrões de acessibilidade como um conjunto de recomendações ou diretrizes que objetivam a criação de conteúdo para Portadores de Necessidades Especiais (PNE). O objetivo da 
padronização é diminuir os problemas de geração de conteúdo e utilização de páginas com conteúdo para Web, tornando esses sites mais acessíveis, facilitando o acesso à informação para esse público específico. Hoje o e-MAG encontra-se em sua versão 3.0, a qual foi desenvolvida e revisada pelo Departamento de Governo Eletrônico e o Projeto de Acessibilidade Virtual da Rede de Pesquisa e Inovação em Tecnologias Digitais (RENAPI) e sua observância é obrigatória nos sites e portais do governo brasileiro (BRASIL, 2011).

$\mathrm{Na}$ página do e-MAG, são explicitados 3 passos para se criar um site acessível. Estes passos são:

- Seguir os padrões Web - neste caso recomenda-se seguir os padrões estabelecidos pelo w3C;

- Seguir as diretrizes ou recomendações de acessibilidade essas diretrizes e recomendações são aquelas definidas pelo WCAG 2.0, porém em nível nacional pode-se seguir o e-MAG;

- Realizar a avaliação de acessibilidade - sugere-se aqui a utilização de validadores automáticos além da validação manual. Neste caso, recomenda-se validar o código HTML, o fluxo de leitura da página, as funcionalidades da barra de acessibilidade e aplicar um checklist (o qual pode ser encontrado em http://www.governoeletronico.gov.br/ acoes-e-projetos/e-MAG/material-de-apoio).

Este checklist é composto de cinco itens:

1. Links;

2. Conteúdos;

3. Formulários;

4. Estrutura do site e;

5. Acessibilidade.

Em relação especificamente ao item acessibilidade sugere-se que esta possa ser avaliada através de quatro observações, que seguem:

1. O site possui a opção de alto contraste? Ela está funcionando corretamente?

2. O site possui uma página com dicas de navegação?

3. Há alguma observação extra sobre acessibilidade, usabilidade e comunicabilidade?

4. O site possui opções para redimensionamento do texto?

Desta forma, este artigo explora estes quatro itens para verificar a acessibilidade do Portal Brasil. Note-se que para avaliação da acessibilidade seria necessário aplicar testes com usuários, o que não é objetivo deste artigo. Assim, propõe-se apenas verificar se as observações propostas foram implementadas no site do governo e também verificar a acessibilidade do site através do documento de 
recomendações WCAG 2.0. Além disto, como o site Portal Brasil sofreu um redesign enquanto este artigo estava sendo escrito, as quatro observações sobre acessibilidade serão comparadas nas duas versões do site, ou seja, na versão anterior (acessada em setembro e outubro de 2013) e na versão atual (acessada em novembro de 2013). Ambas as versões foram acessadas no navegador Firefox.

\subsection{Verificação da acessibilidade em site do governo brasileiro}

O Portal Brasil traz informações sobre o Brasil, e disponibiliza acesso dos cidadãos às informações públicas. Como pretende atingir um público vasto, incluindo pessoas com necessidades especiais, espera-se que a acessibilidade digital possa ser verificada neste Portal.

Para verificar a acessibilidade do Portal Brasil foram aplicados os quatro itens do checklist sugerido pelo e-MAG. Assim, o primeiro item refere-se ao contraste. Na versão anterior, existia a opção "contraste" que, ao ser ativada, alterava o fundo de branco para preto, conforme Figura 2. Este item era atendido parcialmente uma vez que existe ao menos uma opção para alteração de contraste. Porém, o contraste utilizado na versão atual não é a padrão: fundo preto, fonte branca, links amarelos, como determinado pelo e-MAG. O fundo passa para preto com fonte branca, mas os links ficam em azul com fundo preto com baixo contraste, as palavras praticamente invisíveis, como mostrado na Figura 3.

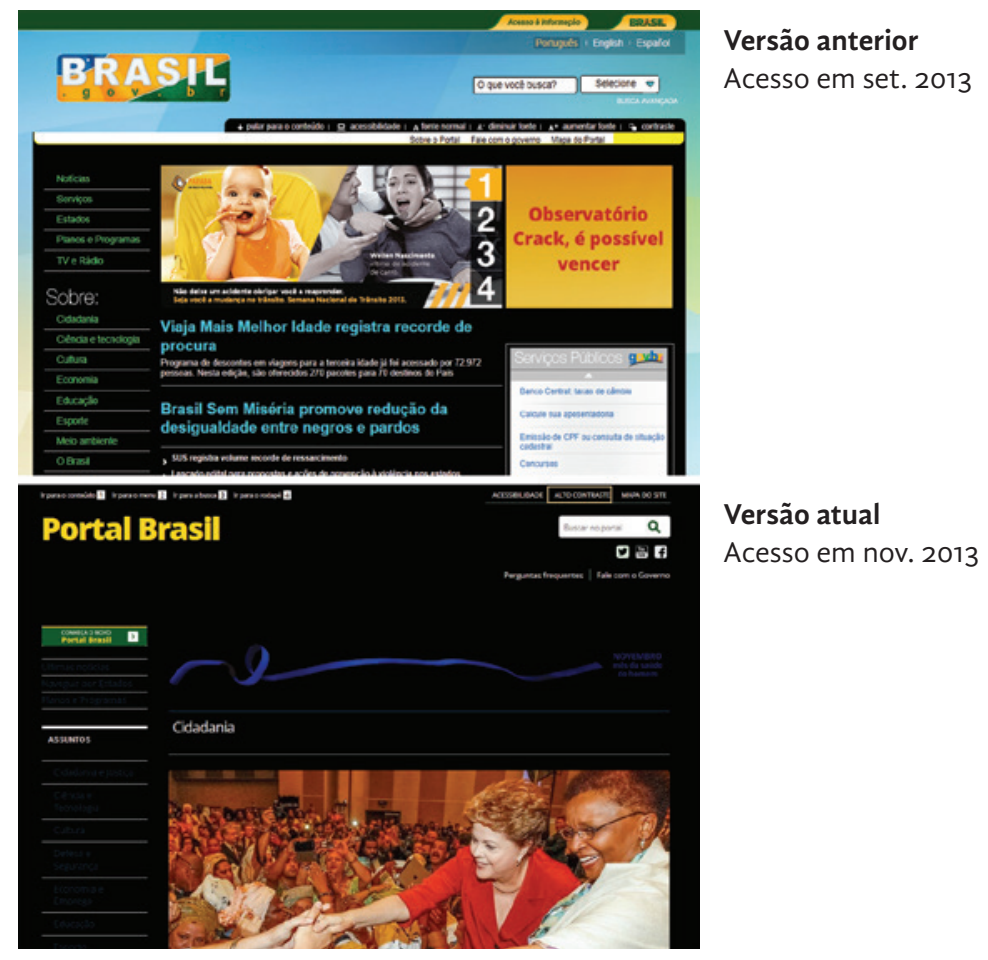

Figura 2 Páginas iniciais do Portal Brasil com alteração de contraste 


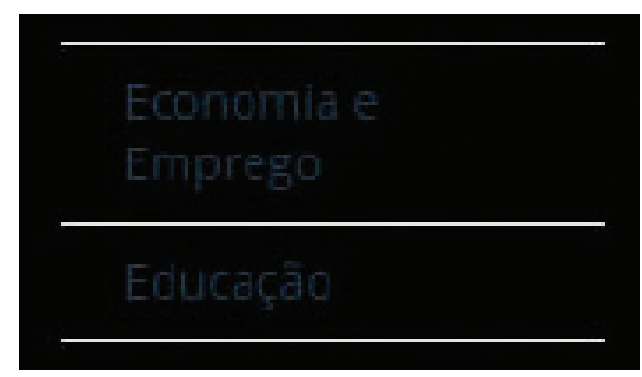

Figura 3 Detalhe dos links após selecionar a opção de "alto contraste" na versão atual do Portal Brasil

Já em relação às dicas de navegação, na versão anterior era apresentado o link "pular para o conteúdo", que com o mouse over fazia surgir um rótulo explicando que para navegação via teclado era para clicar e ir direto para os conteúdos do portal. Porém esta mensagem aparecia com erro, pois os acentos eram traduzidos em caracteres especiais dificultando a leitura. Além disto, a mensagem não era clara.

$\mathrm{Na}$ versão atual, existe uma página intitulada "Acessibilidade", a qual registra os atalhos de teclado para o começo do conteúdo principal da página, para o início do menu principal e para a busca interna. Também são apresentados no canto superior esquerdo os links para ir ao conteúdo, ir ao menu, ir para a busca e para o rodapé. Porém, esses links ficam confusos quando o cabeçalho não é visível e, portanto, não podem mais ser selecionados com o mouse. Nesse momento, a primeira alternativa que se tenta para ir para a busca, por exemplo, é digitar o numero 3 que precede o link "Ir para a busca". No entanto, o número 3 deve ser digitado juntamente com a tecla ALT ou ALT + SHIFT no Firefox, e esta informação só é encontrada na página "Acessibilidade".

Em relação ao terceiro item, o qual trata da observação extra sobre acessibilidade, usabilidade e comunicabilidade, o primeiro desconforto acontece quando se escolhia o idioma inglês na versão anterior. Isso porque o menu de acessibilidade permanecia em português (Figura 4).

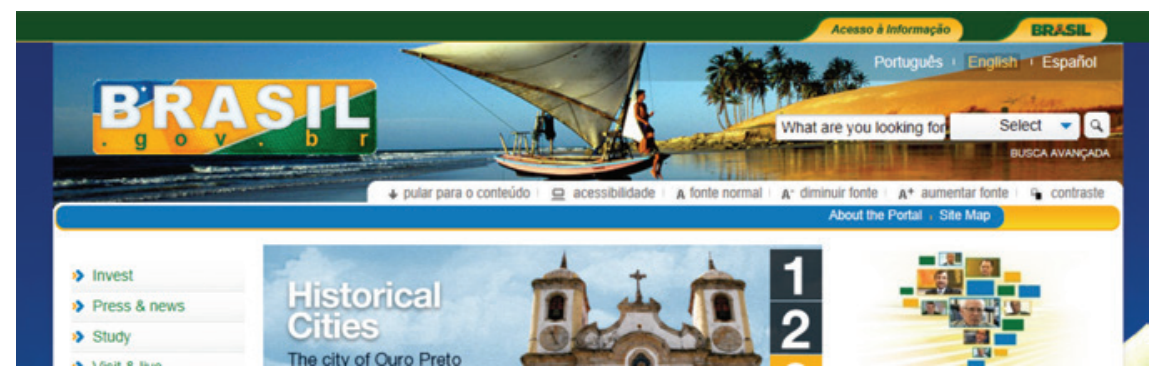

Figura 4 Mudança de idioma com o menu de acessibilidade inalterado. Acesso em set. 2013 
Além disto, na versão anterior o link notícia estava corrompido, levando a uma página de erro (Figura 5). Na versão atual não existe a opções de mudança de idioma e o link "notícias" foi substituído pelo "últimas notícias", o qual não apresenta problemas.

Site Error
An error was encountered while publishing this resource.
Resource not found
Sorry, the requested resource does not exist.
Check the URL and try again.
Resource: http $: /$ www.

Figura 5 Página de erro após clicar no link notícias. Acesso em set. 2013

Com relação o item 4, sobre redimensionamento do texto, existia na versão anterior desse Portal um menu na região superior da página apresentando as opções "fonte normal", "diminuir fonte", "aumentar fonte" e "contraste" (Figura 6).

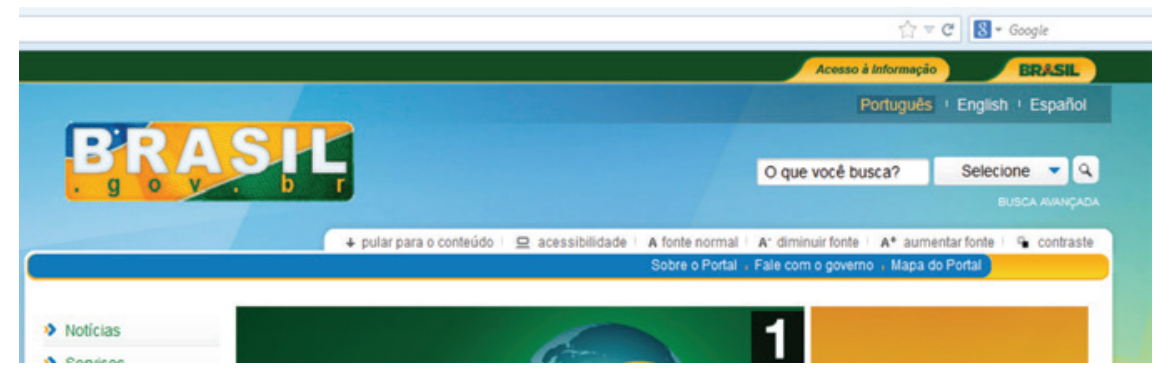

Figura 6 Opções de alteração. Acesso em set. 2013

Porém, percebeu-se que as opções de aumento de fonte ou mudança de contraste nem sempre eram capazes de diminuir a dificuldade de visualização das informações. O aumento de tamanho de uma fonte podia acarretar em desorganização dos blocos de texto e até mesmo no encobrimento do próprio menu que permitia essa ação (Figura 7). 


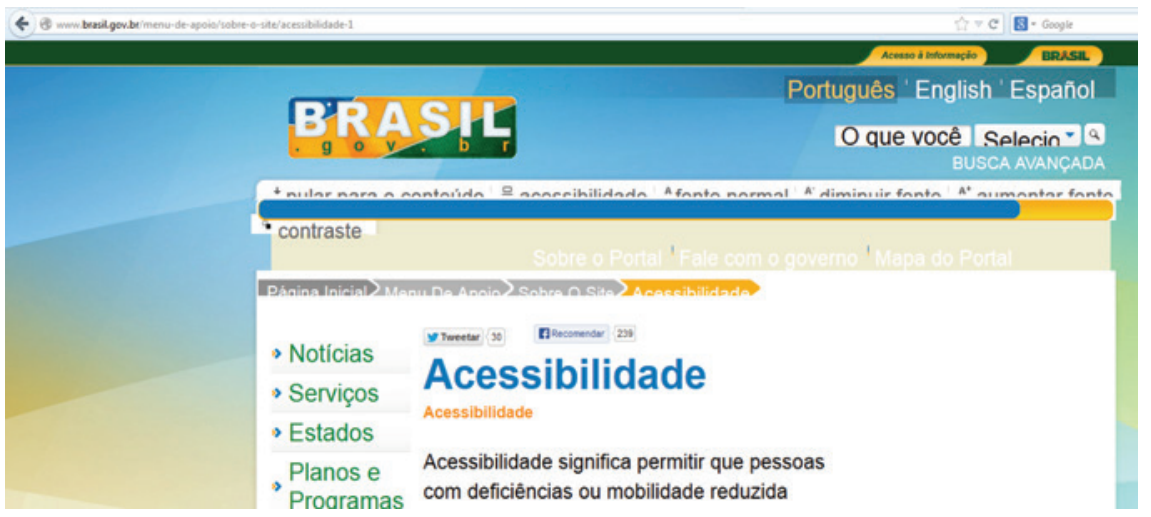

Figura 7 Menu após o incremento no corpo da fonte. Acesso em set. 2013

Na versão atual não existem as opções de tamanho de texto. Mas é possível perceber, mesmo assim, que existe a preocupação com hierarquia e distribuição do texto, uso de colunas (evitando linhas muito longas), de espaçamento normal (entre caracteres, entre palavras e entrelinhas), de textos alinhados à esquerda $\mathrm{e}$ sem hifenização e o uso de poucas variações de tipografia (criando unidade estilística). Quanto à compreensibilidade, percebe-se o uso de um estilo jornalístico nos textos apresentados, em função predominantemente referencial combinada à apelativa, mesclando um tom oficial a um mais íntimo, mas seriam necessários estudos mais aprofundados para verificar a compreensão das mensagens por um público tão heterogêneo.

Embora o Portal não apresente todos os itens sugeridos pelo checklist do e-MAG, foi verificada a acessibilidade através do documento de recomendações WCAG 2.0, como mostrado no Quadro 1. Nesse quadro são apresentadas apenas as Recomendações de Acessibilidade para Conteúdo Web e não se as técnicas e critérios de sucesso foram aplicados. Ou seja, para verificar o princípio perceptível, por exemplo, foram exploradas nas páginas do Portal Brasil as opções sobre alternativas textuais e mídias baseadas no tempo, além de modos diferentes para criar conteúdo e se a audição e visualização de conteúdos foram apresentadas de forma fácil para os usuários. As recomendações de cada princípio, perceptível, operável, compreensível e robusto foram apresentadas na Figura 1, na seção 2 deste artigo. 
Quadro 1 Verificação da acessibilidade pelo documento de recomendações (WCAG 2.0)

\begin{tabular}{|c|c|c|}
\hline Recomendações WCAG 2.0 & Versão Anterior & Versão Atual \\
\hline \multicolumn{3}{|l|}{ Perceptível } \\
\hline $\begin{array}{l}\text { Fornecer alternativas textuais para qualquer } \\
\text { conteúdo não textual, permitindo que possa ser } \\
\text { alterado, se necessário, para outros formatos } \\
\text { como impressão com tamanho de fontes maiores, } \\
\text { Braille, fala, símbolos ou linguagem mais simples. }\end{array}$ & $\begin{array}{l}\text { Fornecidos rótulos, porém } \\
\text { estes apresentavam erros } \\
\text { na acentuação. } \\
\text { Algumas imagens não } \\
\text { possuíam rótulos. }\end{array}$ & $\begin{array}{l}\text { Não são oferecidas alternativas para } \\
\text { conteúdos não textuais. }\end{array}$ \\
\hline $\begin{array}{l}\text { Fornecer alternativas para mídias baseadas } \\
\text { no tempo. }\end{array}$ & $\begin{array}{l}\text { Não foram encontradas } \\
\text { mídias baseadas no tempo. }\end{array}$ & $\begin{array}{l}\text { Os vídeo-áudios disponibilizados } \\
\text { apresentam a opção de legenda } \\
\text { em português. }\end{array}$ \\
\hline $\begin{array}{l}\text { Criar conteúdo que pode ser apresentado } \\
\text { de modos diferentes (por exemplo um } \\
\text { layout simplificado) sem perder informação } \\
\text { ou estrutura) }\end{array}$ & Não verificado no site. & $\begin{array}{l}\text { O layout é responsivo podendo } \\
\text { o Portal Brasil ser utilizado em } \\
\text { diferentes plataformas. }\end{array}$ \\
\hline $\begin{array}{l}\text { Tornar mais fácil aos usuários a visualização e } \\
\text { audição de conteúdos - incluindo as separações } \\
\text { das camadas da frente e de fundo. }\end{array}$ & $\begin{array}{l}\text { Somente o controle } \\
\text { do tamanho da fonte e } \\
\text { com problemas. }\end{array}$ & $\begin{array}{l}\text { Somente as informaç̃̃es no formato de } \\
\text { áudio-vídeo podem ser lidas na forma } \\
\text { de legendas em português e existe o } \\
\text { controle do volume do som. } \\
\text { A opção de contraste altera o fundo para } \\
\text { preto e texto para branco, porém os links } \\
\text { praticamente somem por serem azuis } \\
\text { sobre o fundo preto. } \\
\text { Não existe a opção de controle de fonte. }\end{array}$ \\
\hline
\end{tabular}

\begin{tabular}{lll}
\hline Operável & & \\
\hline $\begin{array}{l}\text { Fazer com que todas as funcionalidades estejam } \\
\text { disponíveis no teclado. }\end{array}$ & $\begin{array}{l}\text { O link não funcionava ou } \\
\text { não foi compreendido. }\end{array}$ & $\begin{array}{l}\text { Existem opções de atalhos de teclado } \\
\text { para de acesso ao conteúdo, ao menu, à } \\
\text { busca e ao rodapé. }\end{array}$ \\
\hline $\begin{array}{l}\text { Prover tempo suficiente para os usuários lerem e } \\
\text { usarem o conteúdo. }\end{array}$ & $\begin{array}{l}\text { A leitura pode tomar o } \\
\text { tempo necessário. }\end{array}$ & $\begin{array}{l}\text { A leitura pode tomar o tempo } \\
\text { necessário. Os vídeos possuem controles } \\
\text { de pausa, tempo e som. }\end{array}$ \\
\hline $\begin{array}{l}\text { Não projetar conteúdo de uma forma conhecida } \\
\text { por causar ataques epiléticos. }\end{array}$ & $\begin{array}{l}\text { Nada que possa provocar } \\
\text { um ataque epilético foi } \\
\text { verificado no site. }\end{array}$ & $\begin{array}{l}\text { Nada que possa provocar um ataque } \\
\text { epilético foi verificado no site. }\end{array}$ \\
\hline $\begin{array}{l}\text { Prover formas de ajudar os usuários a navegar, } \\
\text { localizar conteúdos e determinar onde } \\
\text { se encontram. }\end{array}$ & $\begin{array}{l}\text { Existem 4 formas } \\
\text { de navegação: por } \\
\text { imagens, áudios, vídeos } \\
\text { e infográficos. }\end{array}$ & $\begin{array}{l}\text { A localização do usuário é mostrada } \\
\text { através dos Breadcrumbs. São descritos } \\
\text { os títulos das páginas. }\end{array}$ \\
\hline
\end{tabular}

\begin{tabular}{lll}
\hline Compreensível & \\
\hline $\begin{array}{l}\text { Tornar o conteúdo de texto legível } \\
\text { e compreensível. }\end{array}$ & $\begin{array}{l}\text { Os menus das páginas } \\
\text { internas como em saúde, } \\
\text { eram confusos pois tinham } \\
\text { muitos links. }\end{array}$ \\
\hline
\end{tabular}


Quadro 1 Verificação da acessibilidade pelo documento de recomendações (WCAG 2.0)

\begin{tabular}{|c|c|c|}
\hline Recomendações WCAG 2.0 & Versão Anterior & Versão Atual \\
\hline $\begin{array}{l}\text { Fazer com que as páginas da Web apareçam e } \\
\text { funcionem de modo previsível. }\end{array}$ & $\begin{array}{l}\text { A arquitetura da } \\
\text { informação dificulta a } \\
\text { navegação. }\end{array}$ & $\begin{array}{l}\text { Algumas páginas não apresentam o } \\
\text { menu lateral (como no resultado da } \\
\text { busca). Outras páginas, como os dos } \\
\text { planos e programas, desviam o usuário } \\
\text { para fora do portal. } \\
\text { O “Fale com o governo" desvia o usuário } \\
\text { para as páginas dos setores, como } \\
\text { <http://www.fazenda.gov.br/> e não } \\
\text { abrem um formulário, como se espera. }\end{array}$ \\
\hline Ajudar os usuários a evitar e corrigir erros. & $\begin{array}{l}\text { Existia um link apenas } \\
\text { para relatar erros. }\end{array}$ & $\begin{array}{l}\text { Existe uma página de perguntas } \\
\text { frequentes que pode redimir algumas } \\
\text { das dúvidas dos usuários, e para o } \\
\text { item "Aplicativos" existe um roteiro de } \\
\text { como proceder. }\end{array}$ \\
\hline
\end{tabular}

\begin{tabular}{lll}
\hline Robusto & \\
\hline $\begin{array}{l}\text { Maximizar a compatibilidade entre os atuais } \\
\text { e futuros agentes do usuário - incluindo as }\end{array}$ & $\begin{array}{l}\text { Não foi utilizado em } \\
\text { outras plataformas. }\end{array}$ & $\begin{array}{l}\text { O layout é responsivo, permitindo o uso } \\
\text { em outras plataformas. }\end{array}$ \\
\hline
\end{tabular}

Para que as informações contidas na página possam ser perceptíveis, as recomendações WCAG 2.0 sustentam que as informações apresentadas devem estar em mais de um canal. Ou seja, o que for informação textual deve ser apresentada também em áudio, ou vídeo, etc, enquanto o que for imagem deve estar também na forma de som e vice-versa. Além disto, sugere-se que o layout seja programável e, portanto possa ser adaptado às necessidades do usuário. Isto é em parte resolvido na versão atual por usar um layout responsivo, o que permite a utilização do Portal Brasil em diferentes plataformas como celular e tablet, além do computador. Porém, como mostra o Quadro 1, existem poucas alternativas de apresentação da informação, a não ser que sejam mostradas em vídeo.

Para ser operável, as recomendações WCAG 2.0 determinam que o usuário possa usufruir das funcionalidades do site através do teclado, tendo tempo suficiente para leitura ou para ouvir as informações, e sem risco da apresentação das informações causarem ataques epiléticos. Por fim recomenda-se que para ser operável o site deve ser navegável, ou seja, que seja fácil de localizar os conteúdos e de se localizar no site. Já o princípio de compreensibilidade é verificado se o texto for compreensível, se a navegação for previsível e se houver ajuda para que o usuário corrija e/ou evite os erros. E por fim, o princípio de robustez requer que o conteúdo possa ser interpretado por vários agentes de usuário. 
Como o objetivo era verificar a acessibilidade através das recomendações do WCAG 2.0 optou-se por rever esta verificação acrescentando as opções de cada diretriz para apontar o grau de cumprimento de cada princípio. Desta forma, a diretriz "alternativas em texto" do princípio perceptível, passou a ser investigada através de suas opções - controle e entrada, mídias com base no tempo, teste, sensorial e decoração - foram satisfeitas ou não. Os Quadros 2 a 5 apresentam o resultado desta verificação para os princípios perceptível, operável, compreensível e robusto respectivamente. As opções de cada diretriz foram retiradas do documento do WCAG 2.0 (2012) e sua verificação demandou constante leitura e estudo deste documento, para compreensão do que se pedia em cada opção. Para melhor compreensão dos Quadros 2 a 5, considere-se a seguinte legenda:

$\checkmark=$ observado nas páginas; $\boldsymbol{X}=$ não observado nas páginas;

$\mathrm{NA}=$ não se aplica, pois a funcionalidade não foi implementada.

Quadro 2 Resultado do princípio perceptível

PRINCíPIO 1 | Perceptível - A informação e os componentes da interface do usuário

têm de ser apresentados aos usuários em formas que eles possam perceber.

Resultado

Alternativas em texto: fornecer alternativas em texto para qualquer conteúdo não textual

permitindo, assim que o mesmo possa ser alterado para outras formas mais adequadas

à necessidade do indivíduo, tais como impressão em caracteres ampliados, Braille, fala,

símbolos ou linguagem mais simples.

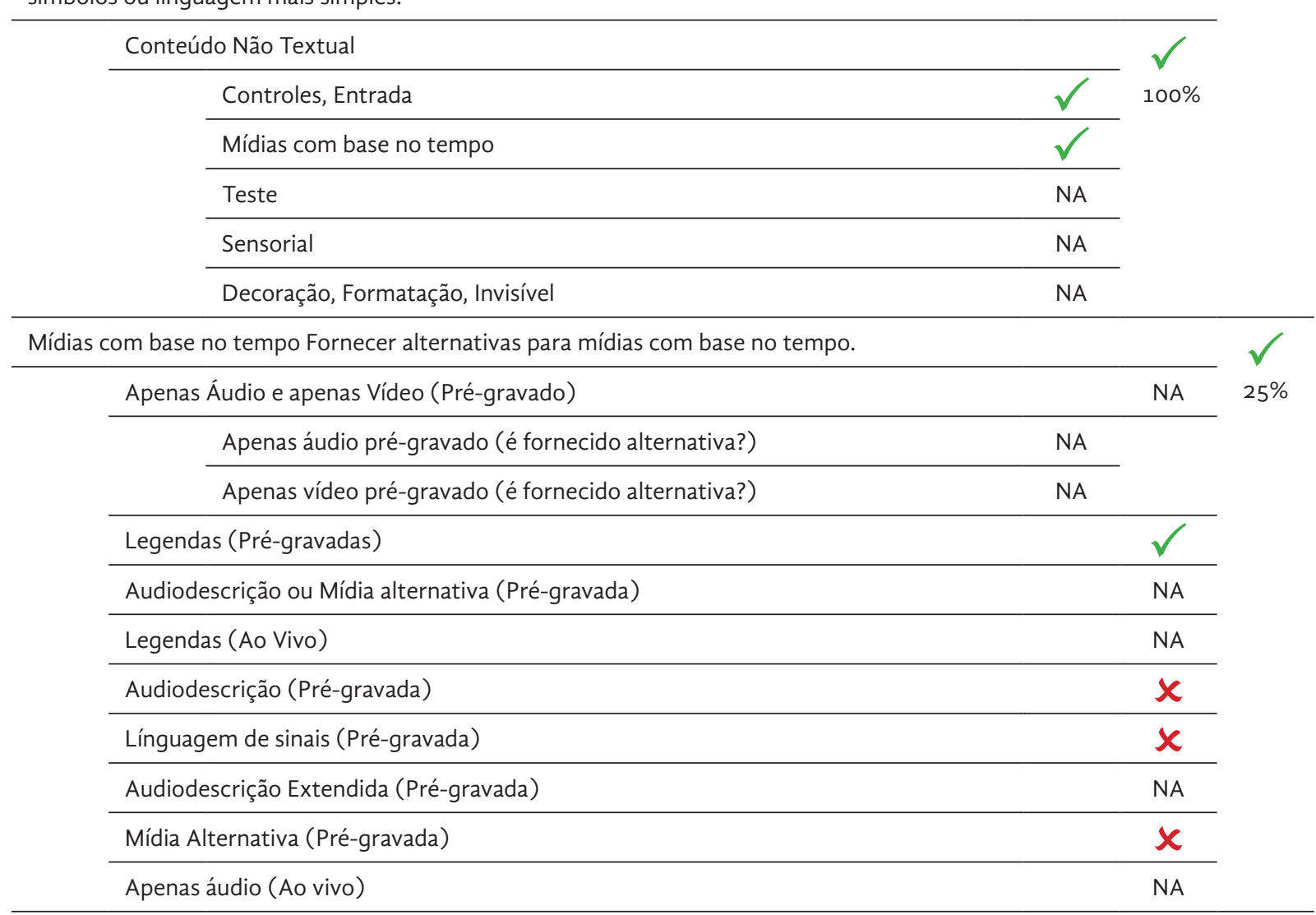


Quadro 2 Resultado do princípio perceptível

PRINCíPIO 1 | Perceptível - A informação e os componentes da interface do usuário têm de ser apresentados aos usuários em formas que eles possam perceber.

Adaptável: criar conteúdos que possam ser apresentados de diferentes maneiras (por exemplo, um layout mais simples) sem perder informação ou estrutura.

\begin{tabular}{lc}
\hline Informações e Relações & $\boldsymbol{x}$ \\
\hline Sequência com Significado & $\boldsymbol{X}$ \\
\hline Características Sensoriais & NA \\
\hline
\end{tabular}

Discernível: facilitar a audição e a visualização de conteúdos aos usuários, incluindo a separação

do primeiro plano e do plano de fundo.

\begin{tabular}{lc} 
Utilização da Cor & \multicolumn{1}{c}{} \\
\hline Controle de Áudio & $\boldsymbol{X}$ \\
\hline Contraste (Mínimo) & $\checkmark$ \\
\hline Texto Ampliado & $\sqrt{ }$ \\
\cline { 2 - 3 } Texto em plano Secundário & $\sqrt{ }$ \\
\hline Logotipos & $\mathrm{X}$ \\
\hline Redimensionar texto & $\mathrm{NA}$ \\
\hline Imagens de Texto & $\mathrm{NA}$ \\
\hline Personalizável
\end{tabular}

\begin{tabular}{l}
\hline Contraste (Melhorado) \\
\hline \begin{tabular}{l} 
Texto Grande \\
\hline Texto em plano Secundário \\
\hline Logotipos
\end{tabular} \\
\hline Sem Música de Fundo \\
\hline Desligar \\
\hline 20 dB
\end{tabular}


Quadro 3 Resultado do princípio operável

PRINcíPIO 2 | Operável - Os componentes de interface de usuário e a navegação têm de ser operáveis.

Resultado

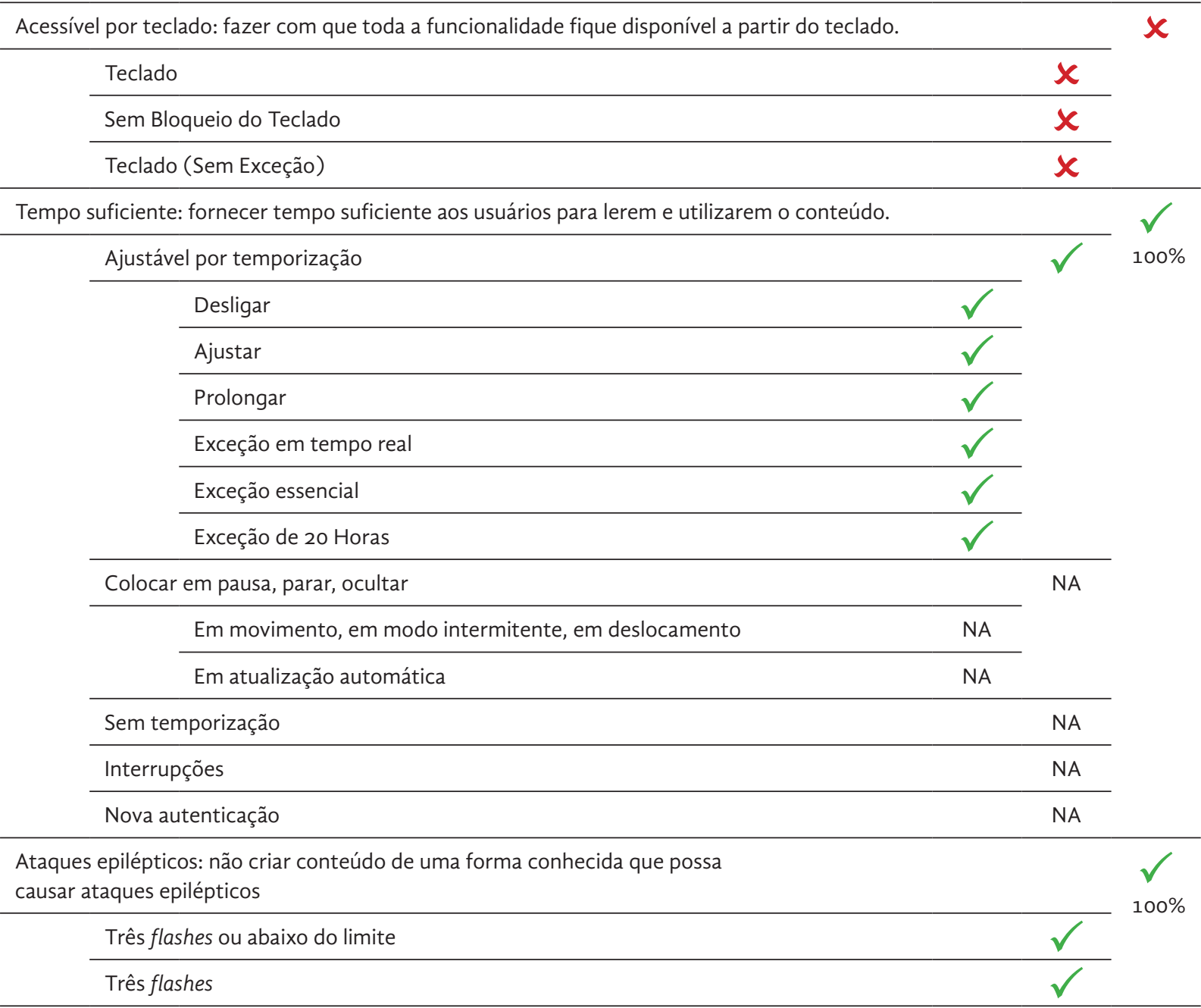

Navegável: fornecer formas de ajudar os usuários a navegar, localizar conteúdos e determinar o local onde estão.

\begin{tabular}{lc} 
Ignorar blocos & $\boldsymbol{X}$ \\
\hline Página com título & $\boldsymbol{X}$ \\
\hline Ordem do foco & $\sqrt{ }$ \\
\hline Finalidade do link (em contexto) & $\checkmark$ \\
\hline Várias formas & $\boldsymbol{X}$ \\
\hline Cabeçalhos e etiquetas & $\sqrt{ }$ \\
\hline Foco visível & $\checkmark$ \\
\hline Localização & $\checkmark$ \\
\hline Finalidade do link (apenas o link) & $\checkmark$
\end{tabular}


Quadro 4 Resultado do princípio compreensível

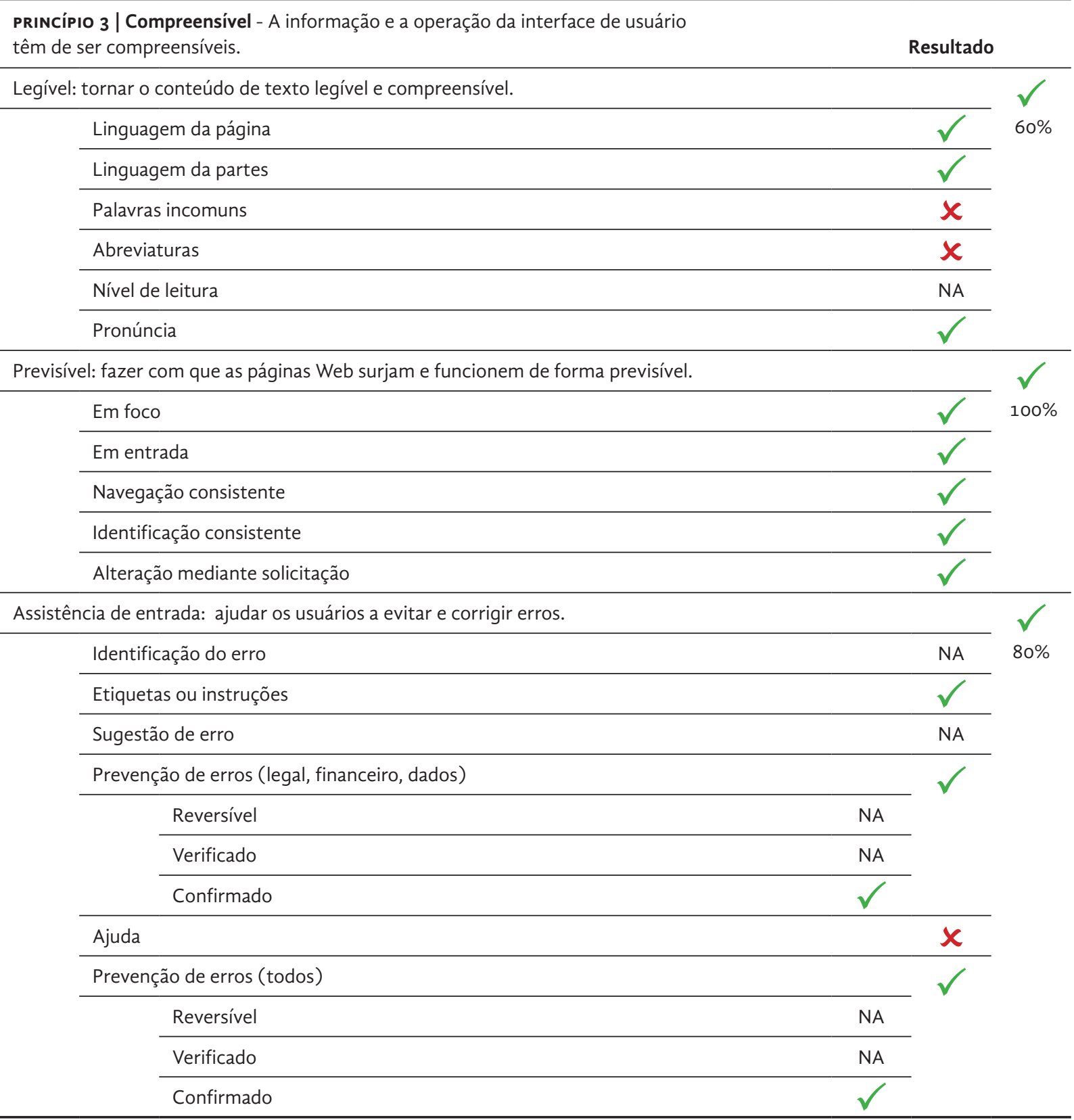

Quadro 5 Resultado do princípio robusto

PRINCí́PIO 4 | Robusto - O conteúdo tem de ser robusto o suficiente para poder ser interpretado de forma concisa por diversos agentes do usuário, incluindo tecnologias assistivas.

Compatível: maximizar a compatibilidade com atuais e futuros agentes de usuário, incluindo tecnologias assistivas.

\begin{tabular}{ll} 
Análise & $100 \%$ \\
Nome, função, valor & $\sqrt{ }$ \\
\hline
\end{tabular}


Os resultados desta verificação pontual sugerem que o princípio "perceptível" que recomenda que "a informação e os componentes da interface do usuário têm de ser apresentados aos usuários em formas que eles possam perceber" não está sendo cumprido em sua plenitude. Isto se deve ao fato de não haver mídias alternativas para um determinado tipo de informação. Além disto, os conteúdos não podem ser apresentados de diferentes maneiras, ou seja, a informação precisa ser programável para poder ser manipulada pela forma de apresentação.

Os resultados do princípio "operável" indicam que somente a opção de utilizar o teclado para agir sobre as funcionalidades da interface parece não ter sido cumprida.

Já os resultados dos princípios "compreensível" e "robusto" indicam que ambos os princípios estão em conformidade com as recomendações da WCAG 2.0.

Estes resultados reforçam as observações feitas no Quadro 1, as quais têm um caráter geral.

\section{Considerações finais}

A acessibilidade tem como seu papel auxiliar no desenvolvimento de um mundo melhor e semelhante para todas as pessoas, ampliando a possibilidade de proporcionar uma experiência satisfatória na utilização de qualquer tipo de interface incluindo páginas para a Web. Interfaces $W e b$, quando idealizadas e desenvolvidas com vistas à acessibilidade, oferecem melhor utilização e interpretação feita pelo navegador que auxilia as tecnologias assistivas a adequar o conteúdo ao público PNE.

Em muitos dos casos, problemas e dificuldades no uso da interface digital podem estar ligados ao design e às restrições de usabilidade e acessibilidade para os usuários que tentam usufruir da informação. Pessoas com deficiência visual, por exemplo, possuem diferentes níveis de dificuldades na visualização de informações, dependendo do grau de deficiência apresentada (de míopes a cegos). Os quatro itens relacionados pelo e-Mag para avaliação da acessibilidade digital tentam cobrir aspectos básicos da interface. Porém, estes itens não são plenamente verificados no Portal Brasil. Isto reafirma a urgência da ética da acessibilidade, quando esta deve ser aplicada, entendida, difundida, verificada e vivenciada.

Além disto, a acessibilidade vai além desses quatro itens e pode ser compreendida com o documento de recomendações (WCAG 2.0). Porém, esse próprio documento pode apresentar problemas de acessibilidade uma vez que sua interpretação é difícil. Isto porque muitos dos problemas de acessibilidade parecem estar ligados à restrições de compreensão da mensagem devido à linguagem utilizada ou à falta de familiaridade do público com a tecnologia. Um exemplo recente é o tablet, que por ter mudado o paradigma de navegação 
causou estranheza e dificuldade no seu uso: os usuários, acostumados com arquivos para organizar seus documentos, tiveram de reconstruir este modelo mental para trabalhar com aplicativos para acessar seus arquivos.

Acessibilidade não diz respeito apenas ao público PNE, mas também está relacionada à promoção de acesso a tecnologias de informação para pessoas de diferentes níveis de percepção, cognição, motricidade, além de diferenças de idade, gênero, classe social, cultura, escolaridade e de experiência no uso de tecnologias de informação e comunicação. A não observância da acessibilidade no espaço digital pode promover a discriminação de milhares de usuários e ampliar a fragmentação social entre cidadãos com e sem acesso à informação e às novas tecnologias.

Facilitar o acesso para todas as pessoas às informações e serviços disponibilizados no ambiente Web não se trata apenas de fazer pequenos ajustes referentes à funcionalidade das interfaces oferecidas ao público como, por exemplo, permitir a ampliação de fontes tipográficas. É preciso consideração e comprometimento dos envolvidos direta ou indiretamente no desenvolvimento dos ambientes digitais, bem como a percepção de que os potenciais usuários desses ambientes têm direito ao seu uso pleno.

Desta forma, torna-se fundamental que os projetos sejam baseados em consultas e envolvimento direto com potenciais usuários dos futuros ambientes. Isso pode implicar na participação dos usuários desde as primeiras fases de desenvolvimento, permitindo que o designer detecte com maior clareza as principais necessidades a serem sanadas.

Um projeto que visa a acessibilidade deve prever flexibilidade no uso da interface, seu uso intuitivo e simplificado, com mínimo esforço físico, perceptivo e cognitivo, em um ambiente com tolerância a erros. O designer tem a reponsabilidade profissional de criar mensagens detectáveis, discrimináveis, atrativas, compreensíveis e convincentes para seu cliente e para público. Mas, para atender às necessidades do público e promover a melhoria de acesso à informação é preciso ir além da competência técnica e reconhecer o outro como sujeito, como intérprete, independente e pensante, com maneiras específicas de entender, avaliar e integrar experiência e informação.

\section{Referências}

BRASIL. (2013). Disponível em: http://www.brasil.gov.br/menu-de-apoio/sobreo-site/acessibilidade-1. Acesso em: set. 2013

BRASIL. (2004). Decreto-lei n⿳⺈ 5296, de 2 de dezembro de 2004. Regulamenta as Leis $\mathrm{n}^{\mathrm{0}} \mathbf{1 0 . 0 4 8}$, de 8 de novembro de 2000 , que dá prioridade de atendimento às pessoas que especifica, e 10.098, de 19 de dezembro de 2000, que estabelece normas gerais e critérios básicos para a promoção da acessibilidade. Diário Oficial da União. República Federativa do Brasil, Brasília, 
DF, 03, dez. 2004. Disponível em: <http://www6.senado.gov.br/legislacao/ ListaPublicacoes.action?id=240147>. Acesso em: jul. 2012.

. (2012). Ministério do Planejamento, Orçamento e Gestão; Secretaria de Logística e Tecnologia da Informação; Departamento de Governo Eletrônico. Padrões Web em Governo Eletrônico: Cartilha de Codificação. Brasília: MP, SLTI, jul. 2010. 48 p. Disponível em <http://www.governoeletronico.gov.br/ biblioteca/arquivos/padroes-brasil-e-gov-cartilha-de-codificacao>. Acesso em: jul. 2012.

. (2011). Ministério do Planejamento, Orçamento e Gestão, Secretaria de Logística e Tecnologia da Informação; Ministério da Educação, Secretaria de Educação Profissional e Tecnológica. e-MAG: Modelo de Acessibilidade em Governo Eletrônico. Brasília: MP, SLTI, 2011.

FERREIRA, M. (2011). (Três motivos para deixar o seu site acessível: As vantagens de possuir um site nas recomendações da w3C. [S.1.]: 12 set. 2007. Disponível em: <http://www.oficinadanet.com.br/artigo/49o/3_motivos_para_ deixar_o_seu_site_acessivel>. Acesso em: out. 2011.

FRASCARA, J. (1996). Diseño gráfico para la gente: comunicaciones de masa y cambio social. Buenos Aires: Infinito.

FREITAS, J. V.; BENJAMIN, M. B.; PASTOR, s. O.(2012). Usabilidade e Acessibilidade para Portadores de Necessidades Especiais na Web. Bahia: FRB, [s.d]. Disponível em: <http://www.frb.br/ciente/Impressa/Info/ 2004.2/ usabilidade.pdf> Acesso em: jul. 2012.

MELO, A.M., BARANAUSKAS, M.C.C. (2006). Design para Inclusão: desafios e propostas. In: Anais do Simpósio sobre Fatores Humanos em Sistema Computacionais, Natal.

REIS, R. (2011). Falando sobre: O que é acessibilidade e suas vantagens. [S.1.: 2012]. Disponível em: <http://renatoreis.net/blog/desenvolvimento-projeto/ falando-sobre-o-que-e-acessibilidade-e-suas-vantagens/>. Acesso em: 27 out. 2011.

w3C. (2013). Diponível em <http://www.w3c.br>. Acesso em: out. 2013 WCAG 2.o. (2012). Disponível em: < http//www.acessibilidade.gov.pt/w3/TR/ WCAG20/>. Acesso em: jul. 2012.

\section{Sobre as autoras}

\section{Lais Cristina Licheski}

<laislic@utfpr.edu.br>

Dra. UTFPR. Atualmente é professora da Universidade Tecnológica Federal do Paraná, em cursos de Tecnologia, Bacharelado e de Especialização na área de Design. Tem experiência na área de Educação, com ênfase em Métodos e Técnicas de Ensino, atuando principalmente nos seguintes temas: comunicação visual, design gráfico, produção gráfica, design de informação, história da arte, mídias eletrônicas e semiótica. 


\section{Luciane Maria Fadel}

$<$ liefadel@gmail.com>

PhD UFSC: Atualmente é professora adjunta do Departamento de Expressão Gráfica da Universidade Federal de Santa Catarina. Tem experiência na área de Design Experiencial com ênfase em Interação Humana-Computador, atuando principalmente nos seguintes temas: design de interação, interface, user experience e animação.

Artigo recebido em 08 out. 2013, aprovado em 12 dez. 2013. 